to many-assimilated with his own. This is followed by a tabulation of the clinical and pathological data on 150 cases, and assorted comments on these; then a chapter on the clinical (including EEG) manifestations; and a selection of detailed case reports, including 'fringe' casesan essential part of the study of a disease the causes and nature of which are unknown.

A final chapter on the neuropathological aspects of the disease includes recent biochemical and electronmicroscopical studies, but was written before the demonstration that at least one form of the disease can be transmitted to experimental animals. The author discusses, and appears to reject, the distinction between Jakob-Creutzfeldt disease and subacute spongiform encephalopathy; but his own views on whether he is dealing with one disease or several are not very clear. Through most of the book, he writes as if he were dealing with a single disease, with variable manifestations, in some ways related to other diseases-for instance, motor neurone disease-but at the end he italicizes the conclusion that ' $\mathrm{J}-\mathrm{C}$ disease is not a unified disease concept'.

The book will be a very valuable work of reference for many years to come. Blemishes include the use of a rather peculiar jargon, which makes many passages difficult to understand; and the grand tabulation of cases contains some errors of fact, of which the reader must beware.

\section{R. OPPENHEIMER}

INTRODUCTION TO CLINICAL NEUROLOGY By Sir Gordon

Holmes. 3rd edition, revised by Bryan Matthews. (Pp. viii +187 ; illustrated. 35s.) Livingstone: Edinburgh. 1968.

The third edition of this well-known text has been edited and revised by Dr. Bryan Matthews. The textual alterations have been quite extensive and some new material has been included, though the total length is only slightly increased. Several new illustrations have been added and old ones removed. The section on convulsions has been revised and appears as a separate chapter headed 'Epilepsy and Loss of Consciousness', surely a retrograde step, for Gordon Holmes often stressed that epileptic attacks were merely one form of involuntary movement and that to consider 'epilepsy' as a disease sui generis was dangerous in the clinical field. A short new chapter on neurology in children has been added, though this contains little information which could not have been scattered judiciously among the text.

Dr. Matthews has done his revision well, and this remains an excellent introduction to neurology for the clinical student. The changes have, inevitably, removed some of the highly original style of Gordon Holmes and many older readers will regret this. Nonetheless, some of the material in the first edition would now be misleading or frankly incorrect, and one could hardly expect an undergraduate to identify these areas. The dilemma as to whether to modernize the text or leave it as a 'period piece' must have been hard to resolve. Many people will agree, however, that Gordon Holmes's approach to the subject has so much to commend it that it was justifiable to make a modernized text available to the present-day student. The first edition will continue to be read by those, now rapidly decreasing in numbers, who knew $Z$ or worked with the author, but I would hope that this $\stackrel{\mathbb{D}}{\subseteq}$ edition will be read by most medical students and not only those interested in neurology.

BRODIE HUGHES

ZUR NEUROANATOMIE UND NEUROPATHOLOGIE DER FRÜH-

FETALZEIT (Monographien aus dem Gesamtgebiete $\frac{\bar{\tau}}{\overline{0}}$. der Neurologie und Psychiatrie, Heft 127). By Hanns

Solcher. (Pp. 78; 39 figures. DM 39). Springer-Verlag:

Berlin, Heidelberg, and New York. 1968.

This monograph is based on the histological examination of the brains of 65 human foetuses ranging in size from 13 to $38 \mathrm{~cm}$ crown-heel length, which corresponds to a gestational age of 14 to 32 weeks. The material consists of $\frac{\bar{\Phi}}{\partial}$ 56 'spontaneous' abortions (the number of pregnancies $\underset{\varrho}{\mathbb{Q}}$ artificially interfered with was not known), four therapeutic abortions, and two foetuses removed from the $\infty$ uterus after the mother's death. The first section contains $\vec{a}$ some observations on the normal development of the brain during the stated period. The striking pathological $\vec{\omega}$ finding is the frequency of intracerebral haemorrhages of various sizes and locations which were found in 61 cases. The author found it difficult to distinguish patho-? logical changes in nerve cells from autolytic changes and cellular pathology is not, therefore, described of i discussed. The author surmises that a foetus may sues $\vec{\theta}$ vive a cerebral haemorrhage contracted in utero and $\infty$ that the destruction of tissue may result in what loof like a congenital malformation. The pathogenesis $\mathscr{F}$ 음 these haemorrhages remains obscure and it is not cle whether they arise before or after delivery. No light has $>$ been thrown on the causes of abortion. Nevertheless th monograph is of interest because so few investigations of this kind have been undertaken.

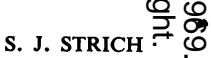

CERVICAL SPONDYLOSIS AND ITS NEUROLOGICAL COMPLICations By B. H. Smith. (Pp. viii +231 ; illustrated. $\$ 12.00)$. Charles C. Thomas: Springfield, Illinois. 1968 . The well-known Thomas Monographs vary greatly in 음 quality, but this is one of the very best, and can be $Q$ warmly recommended. A difficult subject has been $\overrightarrow{\vec{O}}$ handled with skill, good judgement, and clarity. Only a $\frac{0}{3}$ gifted and astute clinician could have succeeded in producing such a helpful and comprehensive study.

ZUKUNFT DER NEUROLOGIE (Future of Neurology)

Edited by H. G. Bammer. (Pp. xii + 262; illustrated.

DM 48.) Georg Thieme: Stuttgart. 1968.

This volume has been prepared as a tribute by over 40 neurologists from all parts of the world to Herr Professor Dr. Georges Schaltenbrand on the occasion of his 70th birthday. Most of the articles are in English and some are of great interest.

THE STRUCTURE AND FUNCTIONS OF THE BRAIN By S. A. Sarkisov. (Pp. xxiii $+291 ; 158$ figures. 93s.) American or

University Publishers Group. 1967.

If this volume is really an up-to-date account of current work, it is disappointing to find that the brilliant Russian 
Neurophysiological School of Pavlov is not really keeping up with current scientific advances in regard to brain mechanisms. It is astonishing, for example, to find so little reference to the exciting discoveries in recent years with regard to the physiology of memory.

SYNDROMES ARTÉRIELS ENCÉPHALIQUES By Georges Manigand. (Pp. viii $+155,7$ figures. 36.00 F.) L'Expansion: Paris. 1968.

French neurologists seem to have special skills in relation to the identification of the clinical syndrome caused by the obstruction of each small artery in the brain. This book will be found a useful work of reference for the clinician who wishes to localize the lesion precisely.

MIND AS A TISSUE Edited by Charles Rupp. (Pp. $x+357$; illustrated. \$16.50.) Hoeber Medical Division, Harper and Row: New York. 1968.

This collection of conference papers has no coherent framework, but it does include interesting experimental work on the effects of surgical excision or ECS on animals, and theoretical discussions of memory processes. The biochemical section is for the specialist, but the volume is possibly of more value to those psychiatrists who are concerned with the physiological basis of - behaviour.

STRUCTURE AND FUNCTION OF INHIBITORY NEURONAL MECHANISMS Edited by C. von Euler, S. Skoglund, and U. Söderberg. (Pp. ix +563 ; illustrated. 185s.) Pergamon Press: Oxford. 1968.

This volume reports the proceedings of the Fourth International Meeting of Neurobiologists held in Stockholm in September 1966. Over fifty papers are reported.

DEUTSCH-ENGLISCHES/ENGLISCH-DEUTSCHES WORTERBUCH FÜR ARZTE Vol. 1. Deutsch-Englisch. By F. Lejeune and Werner E. Bunjes. (Pp. xxiv + 459. DM 64.) Georg Thieme: Stuttgart. 1968.

This is a wonderful new dictionary for doctors and has been compiled from the life-time experience and records of two leading authorities in the skills of accurate translation.

RADIOLOGY IN NEURO-OPHTHALMOLOGY By G. Lombardi. (Pp. viii $+234 ; 167$ figures. 106s.) Williams \& Wilkins: Baltimore. (E. \& S. Livingstone: Edinburgh agents.) 1967.

At first sight it is surprising to read the title of this book for there are many aspects of neuro-ophthalmology which are of no interest to radiology. However, there are important new techniques such as orbitography and venography of the orbit, and the specialist will undoubtedly be glad to refer to this volume from time to time.

SYMPOSIUM ON ORAL SENSATION AND PERCEPTION Compiled and edited by J. F. Bosma. (Pp. ix + 360; illustrated. \$18.50.) Charles C. Thomas: Springfield, Illinois. 1967.
As the neurological study of oral sensation is a somewhat neglected feature of the clinic, this collection of chapters should arouse considerable interest. For example, neurologists will learn with interest how to test oral stereognosis or how to appreciate the oral manifestations of dysdiadokokinesis.

EUROPEAN NeURology, Vol. 1 , No. 1,1968 . Sub. $\$ 16.20$ per annum. Published by S. Karger: Basel.

This new journal of neurology is the continuation of Section B of Psychiatria et Neurologia (previously Monatsschrift für Psychiatrie und Neurologie). This will be published in English and aims 'to develop into a forum for all the neurologists of Europe'. There will be six issues in each year.

LEITFADEN DER NEUROLOGIE By $F$. Laubenthal and $\mathbf{H}$. Schliack. (Pp. xii $+302 ; 77$ figures. DM 29.70.) Georg Thieme: Stuttgart. 1967.

This well-known introduction to neurology was first published in 1941 by $F$. Laubenthal and is now in this eighth edition, revised by a neurologist of a later generation. Attempts to modernize old textbooks are seldom very successful and it might have been better for Dr. Schliack to write a new book entirely by himself. Nevertheless, this is well done and the volume will continue to be popular.

THE VESTIBULAR SYSTEM AND ITS DISEASES Edited by R. J. Wolfson. (Pp. 557; illustrated. 96s.) University of

Pennsylvania Press: Philadelphia. 1966.

Most neurologists find the vestibular system to be a puzzling affair and they will find this report of the Transactions of an International Symposium to be most helpful.

OBSERVATIONS ON THE PATHOLOGY OF HYDROCEPHALUS By

Dorothy S. Russell. Medical Research Council Special

Report Series 265. (Pp. 152; illustrated. 45s.) Her Majesty's Stationery Office: London. 1967.

Professor Dorothy Russell's work on hydrocephalus is well known to neurologists and was published in 1949 as a Special Report to the Medical Research Council. It has been out of print for 10 years, but in response to a persistent demand has now been reprinted with an additional later paper on hydrocephalus included as an appendix. This will be very welcome as the work is of great importance to all who deal with these problems.

DIE THALIDOMID-POLYNEURITIS By Ellen Gibbels. (Pp. vii $+140 ; 4$ figures, 47 tables. DM 27.00.) Georg Thieme: Stuttgart. 1968.

Many practitioners regret that the alarming embryopathy caused by thalidomide in pregnant women led to the withdrawal of a valuable hypnotic drug for others. It is, however, probable that its popularity would soon have waned as the prevalence of peripheral neuropathy became more widely appreciated. A remarkable number of publications on this aspect, mainly German and British, testify to the importance of this toxic effect. Unfortunately, the recent upsurge of interest in the 
detailed pathogenesis of neuropathies came when the drug was withdrawn from general use. In this short monograph the author has gathered together the extensive literature about the clinical features of the predominantly sensory neuropathy. The discussion on pathogenesis and histopathology is an abstract of opinions expressed by various authors, but does not add new material or reach satisfactory conclusions. Most workers postulate an enzyme block or competitive inhibition of a B-group vitamin, but final proof is absent. Even the question whether the lesion is a primary neuronal degeneration or segmental demyelination is undecided. Toxicologists still studying thalidomide with newer methods will find this a useful summary of the literature, but it is now of only historical interest to clinicians.

\section{J. A. SIMPSON}

BRITISH MEDICAL BULLETIN Vol. 25, No. 1, January 1969: NEW ASPECTS OF HUMAN GENETICS. Scientific Editors: C. E. Ford and Harry Harris. (40s.) Medical Department, The British Council, London, W.1. 1969.

This excellent issue of the British Medical Bulletin has been admirably planned by a committee headed by Dr. W. M. Court-Brown. The 16 papers included are by 19 leading geneticists, clinical and population cytogeneticists, biochemical geneticists, and specialists in the genetic aspects of blood-groups, haemoglobin, common malformations and common disorders, as well as thalassaemia, porphyria, and homocystinuria. An enormous amount of important information and comment is presented and will be widely welcomed and referred to.

BRAIN MECHANISMS UNDERLYING SPEECH AND LANGUAGE Proceedings of a Conference held at Princeton, New Jersey, 9-12 November 1965. Supported by a grant from the National Institute of Neurological Diseases and Blindness. By C. H. Millikan and F. L. Darley. (Pp. 261 ; illustrated. \$7.75.) Grune and Stratton: New York and London. 1967.

This Conference brought together in November 1965 many leaders of current thought concerning the physiology of speech and language. For neurologists it will suffice to mention, as contributors, names such as Hécaen, Rosadini, Brenda Milner, Teuber, Sperry, Geschwind, Ettlinger, Magoun, Benton, and Masland, for the high quality and interest of this volume to be appreciated.

NEURological NURSING 2nd edition. By J. Marshall and Jean Mair. (Pp. $\mathrm{x}+174 ; 74$ figures. 25s.) Blackwell Scientific Publications: Oxford. 1967.

This is a useful volume for nurses to study and will be found in most neurological wards. Figures 24, 25, and 26 are very indistinct. Figure 12 is out of date, for foam packs are available to form the 'bales' and of course are much better. This figure should also show support for the patient's head.

PROGRESS IN NEUROLOGICAL SURGERY Vol. 2. Edited by H. Krayenbühl, P. E. Maspes, and W. H. Sweet. (Pp. $\mathrm{x}+$ 406; 104 figures, 31 tables. 170s.) Karger: Basel and New York. 1968.
The second volume in this series deals with aspects of intracranial tumours, largely of the glioma group. There are chapters on the pathology and classification of gliomas, tissue culture of gliomas, nervous system tumours in animals, chemical composition of brain tumours, immunological aspects and radiotherapy of tumours, and a comparison of air studies, angiography, and isotope scans in diagnosis. The editors state that they had asked contributors to produce a critical summary of world literature on their subject and to leaven this with their own experience and that derived from contacts with other workers. Some contributors have satisfied this brief, but others have used their space to put forward their own individual views at length. In the chapter on pathology and classification of gliomas by Zulch and Weschler, most of the space is devoted to a statement of their particular views on this subject, often with detailed consideration of histology which might be tedious to the neurosurgeon. Some of the views put forward by these authors are not widely accepted by other neuropathologists and this disagreement is not made sufficiently clear in the text.

The chapter on tissue culture in gliomas by Kersting makes fascinating reading and is also a model of clear, concise, and elegant writing. He has used the classification put forward by Zulch and it is interesting to note that his work largely supports this system of classifying gliomas.

Chapters on chemical composition and metabolism in brain tumours (P. E. Maspes and P. Paoletti) and orf immunology (L. C. Scheinberg and J. M. Taylor) de provide a critical review of these subjects without the interposition of very personal ideas. Both these subjects seem to be in an early formative state and provide muck of interest but little of immediate practical value to the surgeon.

The chapter on radiotherapy is also an objective review of the present views on this form of therapy and provides little that is new to the experienced clinician. The same may be said of the chapter comparing the value of air studies, angiography, and isotope scans in the diagnosis of gliomas. This is dealt with in some detail and gliomas in various situations described separately. It is done very well and the information about various isotopes is valuable. The conclusions are those reached by most neurosurgeons from experience and add little to the sum total of knowledge.

There is an interesting chapter on nervous system tumours in animals; most of the known tumours in man also occur in animals, though there are species differences and many tumours which cannot be easily classified in human terms.

This book provides useful and modern views on the pathology of nervous system tumours and will be a valuable reference work for some years to come. The illustrations, which are numerous, are all excellent and the bibliographies after each chapter both voluminous and comprehensive. The outstanding chapter, both in content and style, is that on tissue culture and this at least should be read by all neurosurgeons and neuropathologists.

BRODIE HUGHES 